\title{
LOCATION BASED ATTENDANCE MONITORING SYSTEM
}

\author{
Aayushi Singh, Tanya Goel, Deepali Srivastava, Astha Singh \\ Computer Science Engineering, B. tech \\ IMSEC, Ghaziabad, Uttar Pradesh, India \\ Ms. Shivani Agarwal \\ Assistant Professor, Computer Science Engineering, B. tech \\ IMSEC, Ghaziabad, Uttar Pradesh, India
}

\begin{abstract}
Attendance systems were developed a long time ago. Traditional methods like maintaining registers and having a web portal for attendance are used at most of the places even now. This paper will discuss the fingerprint and geo-fence technique and its implementation for Mobile Attendance android-based application.

Managing student attendance during lecture periods has be- come a difficult challenge. The process of computing attendance manually is a difficult job which has to be done on a daily basis and at various levels. An efficient attendance management system using biometrics is designed in order to solve this issue. This process eliminates the need for stationary materials and personnel for keeping records. The results obtained from this system are more accurate and will save a lot of time. Attendance is marked after student identification and uses geofencing to restrict area. Teachers will use their own smartphones for marking the attendance and their attendance will also be marked then and there only.
\end{abstract}

\section{Keywords - Attendance, Geofencing, Biometric}

\section{I.INTRODUCTION}

In many institutions as described in work by (Shoewu $\mathrm{O}$. and Idowu O.A. et al. 2012), and academic organizations, attendance criteria are being used for various purposes. These purposes include keeping of records, assessment of students, and for consistent attendance promotion. Attendance keeping is a time-consuming process and it also decides the number of students eligible to sit for the exams. Thus, there is a need for an efficient system that can solve this problem.

An automatic attendance management system using biometrics would provide the needed solution. An attendance management system is a software developed for daily students and teacher's attendance in schools and institutions. This system maintains a record of the attendance of students as well as teachers. Things get cumbersome when we use cameras (face detection schemes) for attendance or when we use RFID cards as described in work by (Shoewu O. and Idowu O.A. et al. 2012) because the expense of these systems at large levels is not affordable.

The software and hardware are compatible. Web based portals as well as Android apps have been developed to make things easy. Teachers will take attendance of the students using the installed app on their smartphones. The prints will be stored in the database that will do the matching part for further process.

System will help in generating reports at software level, discusses the operations and how the system was tested with reference to system design and functional objectives; concludes the observations made; and makes recommendations for future improvement.

\section{RELATED WORK}

Managing attendance has always been a big issue and it has involved various methods and techniques to make justice to it. Various types of applications use GPS for tracking. GPS allows an object to be tracked by detecting the GPS unit that is installed in a device as described in work by (Makhtar M, Rosly R, Fadzli S. A.,Shamsuddin S. N. W. and Jamal A. A. et al. 2016). When a person carries the device, the satellite can detect the GPS location. Nowadays, most smartphones already embed a GPS unit. In the article "The effects of information technology on human resource management and utilization", Ren emphasized that the flourishing of information technology leads to a quantitative and qualitative revolution within an organization, an industry and inter-industries.

Biometrics is a measurable biological feature or personal trait that can be verified through automated means to confirm a person's identity. Thus, biometric recognition is a technology to prove a person's identity through personal traits. A portion of the body must be provided as the basis of comparison and to keep a biological record. 
In the process of authentication, the biometrics of the user is captured again and the extracted features are compared with the ones already captured and are matched in the database to determine the common match. This identification accuracy of a biometric system is measured with the false acceptance rate and the false reject rate. The False acceptance rate /False rejection rate ratios depend, among other factors, on the type of difficulty of the algorithms used in the fingerprint extraction.
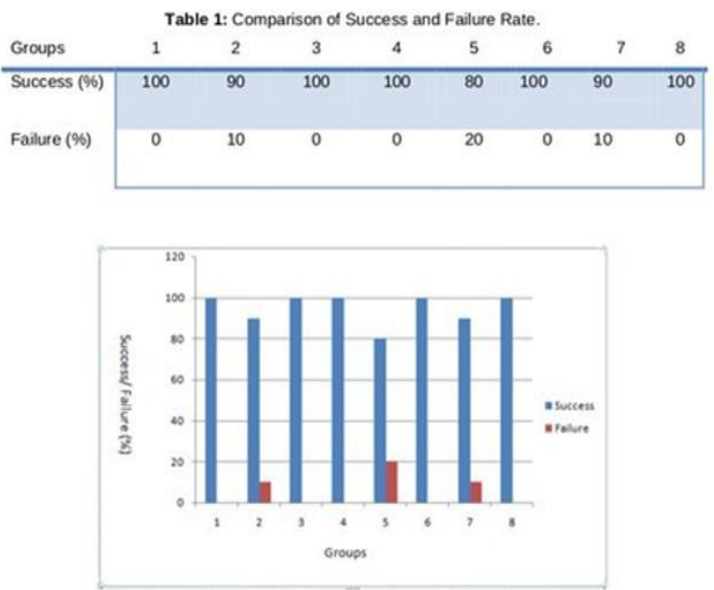

Figure 1: Comparison of Success and Failure Rate as described in work by (Shoewu O. and Idowu O.A. et al. 2012)

\section{GEO-FENCING}

Geofencing as described in work by (Makhtar M, Rosly R, Fadzli S. A.,Shamsuddin S. N. W. and Jamal A. A. et al. 2016) is a sophisticated time management system with geofencing capability that helps track student attendance in real-time. It enables organizations to record the attendance of students from any location. Students will have to be there in this area to submit clock-in and clock-out of their shift. By setting a range of exactly where and when the students will be able to clock-in/out. When a device crosses the boundaries, which are being defined and enters (or exits) that area, application will trigger. Student attendance can be marked via mobile once they enter the building or its defined radius. In case there are any issues, students can send notifications in real time, from the mobile app. Apart from clock-in/clock-out process, geofencing gives the ability to monitor your students' location in real time based on their GPS location, and have them do a set of safety checks to let us know everything is going well at the school. Students can only clock in or clock out within the boundary.
Summary of System Comparison

\begin{tabular}{|c|c|c|c|}
\hline Year & Author & Technology & Result \\
\hline 2012 & $\begin{array}{l}\text { Tsai-Cheng Li, } \\
\text { Huan-Wen Wu, } \\
\text { Tiz-Shiang Wu } \\
\text { et al., } 2012\end{array}$ & $\begin{array}{l}\text { The study of } \\
\text { Biometrics } \\
\text { Technology et } \\
\text { al., } 2012\end{array}$ & $\begin{array}{l}\text { Statistics shows } \\
\text { upon the survey } \\
\text { that the } \\
\text { respondents } \\
\text { mostly agree } \\
\text { using the hand } \\
\text { geometry to } \\
\text { capture } \\
\text { attendance et } \\
\text { al., } 2012\end{array}$ \\
\hline 2016 & $\begin{array}{l}\text { M. Makhtar, R. } \\
\text { Rosly et al., } \\
2004\end{array}$ & Geofencing & $\begin{array}{l}\text { Cost effective } \\
\text { when the user } \\
\text { is away. } \\
\text { The IMEI } \\
\text { number } \\
\text { transferred } \\
\text { Makes the task } \\
\text { very easy.[4] }\end{array}$ \\
\hline 2000 & $\begin{array}{l}\text { Ahmad Raza } \\
\text { Shafqat Hameed } \\
\text { Tim Macintyr et } \\
\text { al., 2016 }\end{array}$ & $\begin{array}{l}\text { Global } \\
\text { Positioning } \\
\text { System }\end{array}$ & $\begin{array}{l}\text { Tendencies of } \\
\text { transferring the } \\
\text { data packet } \\
\text { using GPRS to } \\
\text { the server are } \\
\text { high et al., } \\
2016 \text {. }\end{array}$ \\
\hline 2009 & $\begin{array}{l}\text { T.S Lim, S.C } \\
\text { Sim, M.M } \\
\text { Mansor et al., } \\
2009\end{array}$ & $\begin{array}{l}\text { RFID based } \\
\text { attendance } \\
\text { system }\end{array}$ & $\begin{array}{l}\text { Students et al., } \\
2009 \text { tend to } \\
\text { lose or damage } \\
\text { their cards so } \\
\text { this system can } \\
\text { not } \\
\text { performed } \\
\text { without their } \\
\text { card. }\end{array}$ \\
\hline
\end{tabular}


International Journal of Engineering Applied Sciences and Technology, 2020

Vol. 5, Issue 1, ISSN No. 2455-2143, Pages 513-516

Published Online May 2020 in IJEAST (http://www.ijeast.com)

\begin{tabular}{|c|c|c|c|}
\hline 2015 & $\begin{array}{l}\text { Devendra Kumar } \\
\text { Yadav, Sumit } \\
\text { Singh, Prof. } \\
\text { Shashank Pujari, } \\
\text { Pragyan Mishra } \\
\text { et al., } 2015\end{array}$ & $\begin{array}{l}\text { Fingerprint } \\
\text { Based } \\
\text { Attendance } \\
\text { System Using } \\
\text { Microcontroller } \\
\text { and LabView }\end{array}$ & $\begin{array}{l}\text { The attendance } \\
\text { can save each } \\
\text { student's } \\
\text { fingerprint, } \\
\text { hence makes } \\
\text { the system } \\
\text { more robust. } \\
\text { During } \\
\text { enrolment the } \\
\text { student's } \\
\text { fingerprints are } \\
\text { assumed to be } \\
\text { clean, not dry or } \\
\text { damp, no } \\
\text { scratches and } \\
\text { not swollen et } \\
\text { al., } 2015\end{array}$ \\
\hline
\end{tabular}

\section{Methodology}

This proposed attendance management system uses fingerprint identification as described in work by (Shoewu O. and Idowu O.A. et al. 2012). In identification, the system recognizes an individual by comparing his/her bio metrics with every record. This proposed attendance management system uses fingerprint identification. Every individual is recognized by comparing his/her biometrics with the bio-details stored in the database in the identification process. Biometric identification consists of two stages:

- Enrolment

- Authentication

The enrolment process is carried out by an administrator in the attendance system. After feature extraction, a student is registered using his/her ID and fingerprints are also registered in the database.

This is the main objective of an administrator as described in work by (Shoewu O. and Idowu O.A. et al. 2012) of the enrolment module. A template is formed by these features which is used to determine the identity of the student, which helps in the process of authentication. Administrator carries out the enrollment process in the attendance system. An administrative phase is the registration and enrolment phase in which log in is done by the administrator. All data and information are enrolled which is required for the proper recording of attendance and other bio-details are stored in the database.

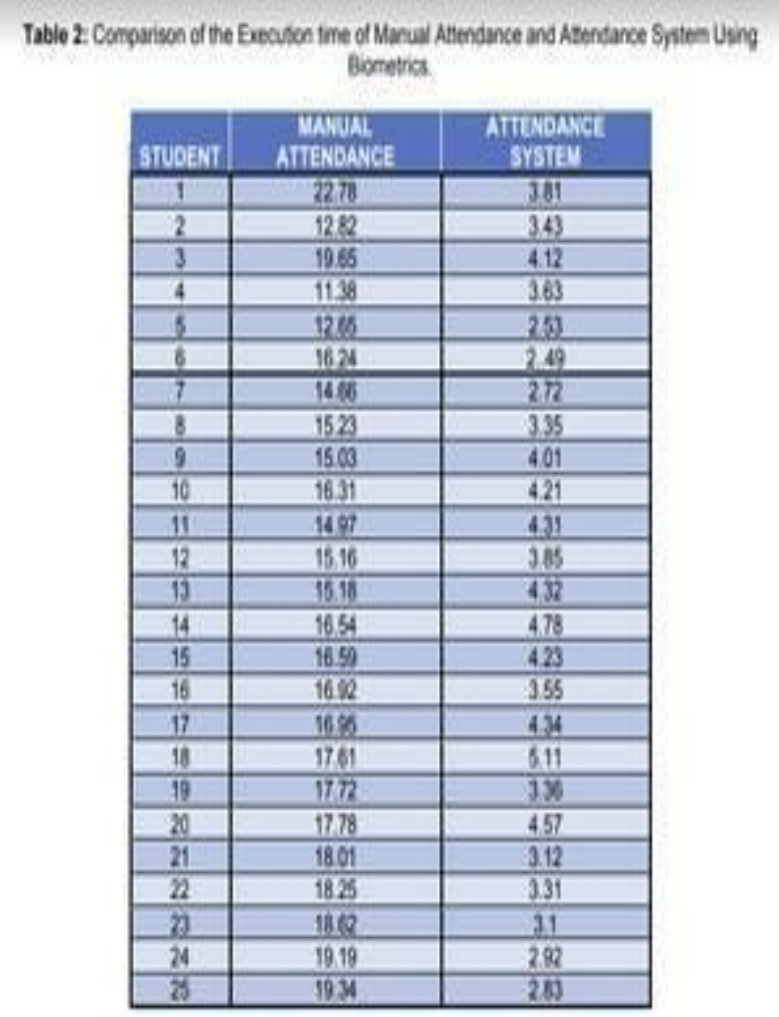

Figure 2: Comparison of Manual Attendance with Attendance Management System as shown by, the work of (Shoewu O. and Idowu O.A. et al. 2012)

The registration and enrolment phase as described in work by (Shoewu O. and Idowu O.A. et al. 2012) is an administrative phase in which the administrator has to log in. The exams, lectures topics and courses are also registered at this phase. All data and information which is required for the proper recording of attendance are enrolled. The teacher selects the attendance type and the course code and, then the student places his/her fingerprint features with the records stored in the database. Below are two possible cases:

Match (of Fingerprint): The fingerprint features which are captured are matched with stored fingerprint templates. The user is automatically recorded for that particular semester exam/mid-semester test/lecture. To show that the user has been recorded for the attendance, a message pops up for a short interval.

Non-match (of fingerprint): When the fingerprint does not match, the user is not accepted for attendance and a message pops up in the textbox showing that fingerprint is not found. 


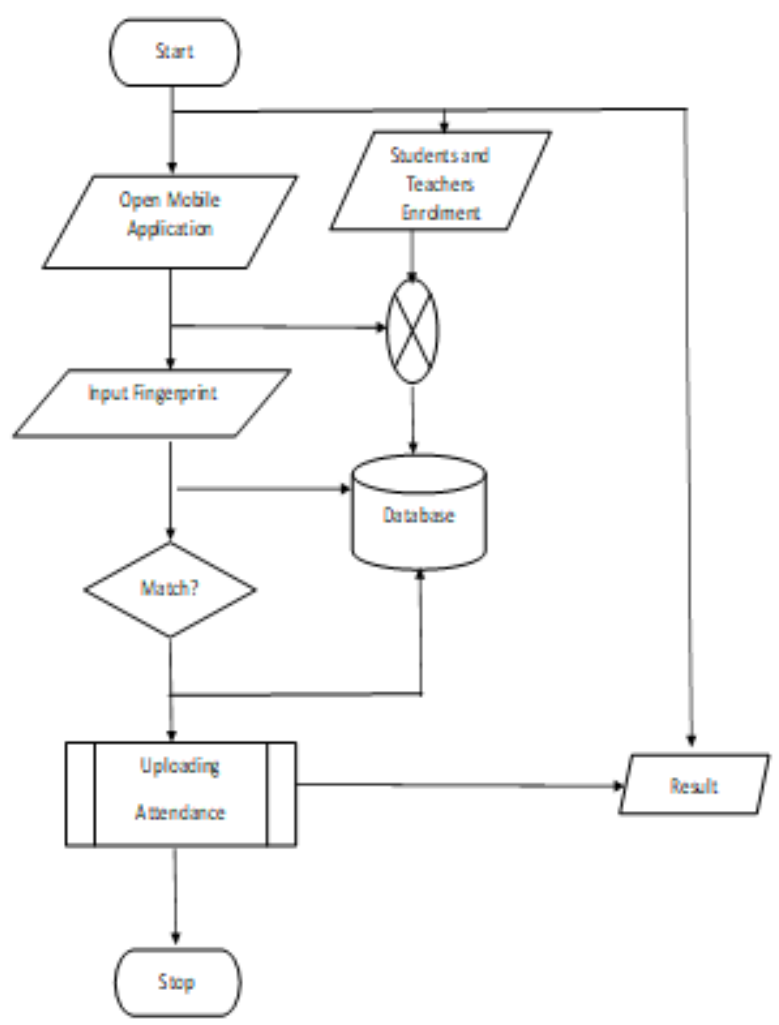

Figure 3: Flowchart of the Process

\section{RESUlTS AND DisCUSSION}

The test results show that the system is efficient and it has a fast response. There was no mislead of information in identifying the students.

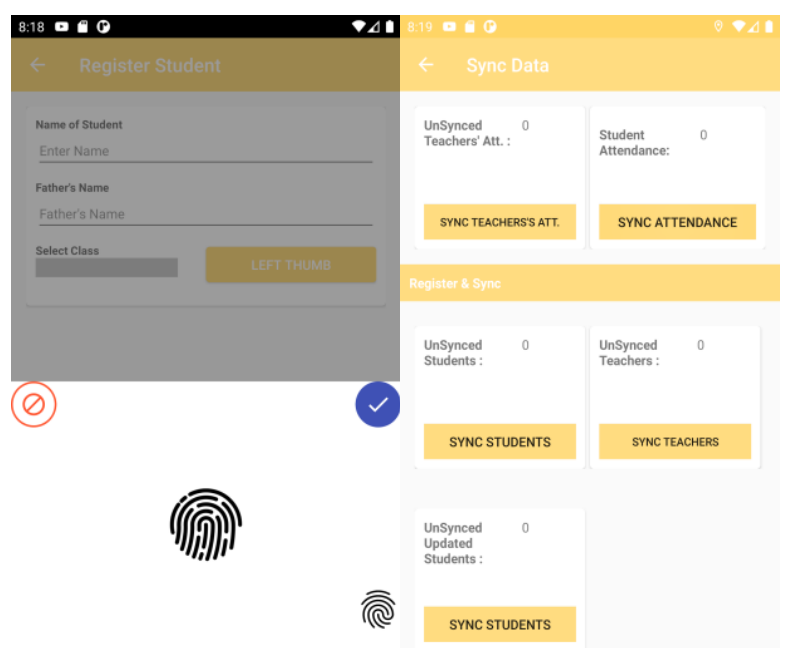

Figure 4: Snaps of Teacher's Data and Enrolment of Students.

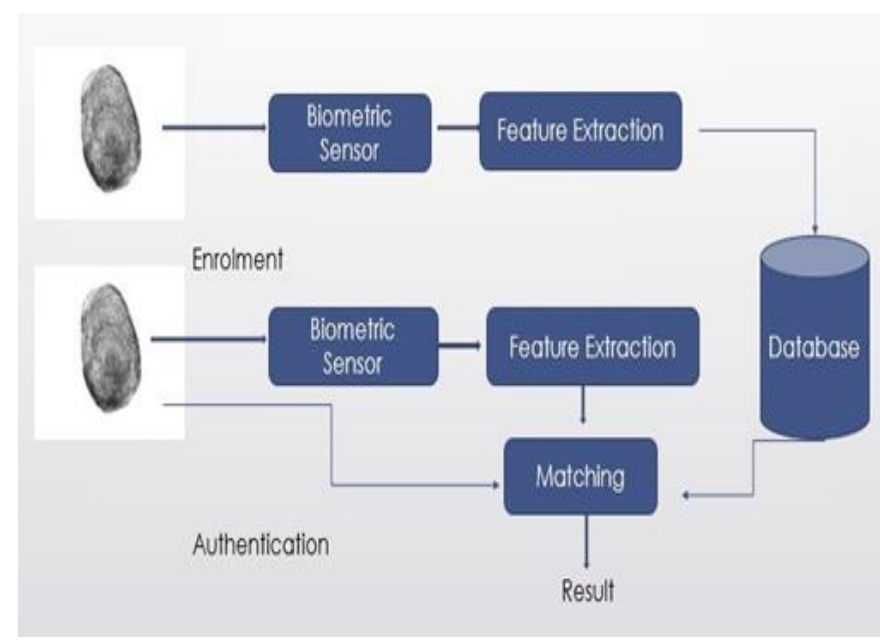

Figure 5: Biometric Architecture as described by (Shoewu O. and Idowu O.A. et al. 2012)

\section{CONCLUSION}

The system was able to match the expectations. It took attendance of both teachers and students. It reduced the extra efforts required for maintaining the records and to examine the minimum eligibility criteria to appear in exams. It would be very effective in government schools.

\section{Acknowledgements}

We wish to acknowledge our mentor and our Head of Department Mr. Pankaj Agarwal for their thorough supervision, suggestions and inputs made in the course of this research.

\section{REFERENCE}

[1] Shoewu O, Ph.D.1,2* and Idowu O.A( May 2012), B.Sc. 1 "Development of Attendance Management System using Biometrics." The Pacific Journal of Science and Technology. 13(1): P 300-307.

[2] Li Tsai-Cheng, Wu Huan-Wen ,Wu Tiz-Shiang (2012) "The study of Biometrics Technology Applied in Attendance Management System".

[3] Mittal Yash, Varshney Aishwary ,Aggarwal Prachi , Matani Kapil and Mittal V. K.(2015) "Fingerprint Biometric based Access Control and Classroom Attendance Management System" Vol. 1.

[4] Makhtar M, Rosly R, Fadzli S. A.,Shamsuddin S. N. W. and Jamal A. A.(March 2016) "Implementation of mobile attendance Application Using Go-fence technique".

[5] Ahmad Raza, Shafqat Hameed, Tim Macintyer (2008),"Global Positioning System" pp: 11-19. 
[6] Lim T.S ,Sim S.C, Mansor M.M(2009)," RFID based attendance system", Vol. II.

[7] Kumar Yadav Devendra , Singh Sumit, Prof. Pujari Shashank, Mishra Pragyan (June 2015), "Fingerprint Based Attendance System Using Microcontroller and LabView" Vol III.

[8] S. Asha and C. Chellappan(2012)Biometrics,": An overview of the Technology,Issues and Applications," International Journal of Computer Applications, vol. 39, no. 10,pp. 35-52.

[9] E. Spinella(2003) "Biometric Scanning Technologies: Finger, Facial and Retinal Scanning," SANS GSEC, Online Submission, San Francisco.

[10] C. Barral(2010) "Biometrics \& Security," pp. 2-5 .

[11] B. Institute, (2015) "Where are biometrics used?" .

[12] A. Jain, Y. Chen, and M. Demirkus (Jan 2007) "Pores and Ridges: High-Resolution Fingerprint Matching Using Level 3 Features," IEEE Transactions on Pattern Analysis and Machine Intelligence, vol. 29 , no. 1 , pp. $15-27$. 